\title{
Article \\ Facial Anti-Aging Treatments with Soft Peeling and Microneedling Technique
}

\author{
Roberto Amore ${ }^{1}$, Fiorella Deriu ${ }^{2}$, Andrea Sbarbati ${ }^{1}$, Domenico Amuso ${ }^{3}$, Massimo Vitale ${ }^{4}$, Ilaria Patruno ${ }^{5}$, \\ Anna Perna ${ }^{6}$ and Antonio Scarano $7,8, *$ (D) \\ 1 Department of Neurosciences, Biomedicine and Movement Sciences, Anatomy and Histology Section, \\ School of Medicine, University of Verona, 37129 Verona, Italy; robertoamore@hotmail.com (R.A.); \\ andrea.sbarbati@univr.it (A.S.) \\ 2 Private Practice, 07100 Sassari, Italy; fiorella.deriu@gmail.com \\ 3 Private Practice, 37134 Verona, Italy; d.amuso.estetica@gmail.com \\ 4 Private Practice, 40138 Bologna, Italy; drmassimovitale@gmail.com \\ 5 Private Practice, 57022 Livorno, Italy; ilariapatruno91@hotmail.it \\ 6 Private Practice, 80132 Napoli, Italy; annaperna09@gmail.com \\ 7 Department of Innovative Technologies in Medicine \& Dentistry, University of Chieti-Pescara, \\ 65127 Pescara, Italy \\ 8 Department of Medical, Oral and Biotechnological Sciences, University of Chieti-Pescara, Via dei Vestini 31, \\ 66100 Chieti, Italy \\ * Correspondence: ascarano@unich.it; Tel.: +39-087-1355-4084; Fax: +39-087-1355-4099
}

Citation: Amore, R.; Deriu, F.; Sbarbati, A.; Amuso, D.; Vitale, M.; Patruno, I.; Perna, A.; Scarano, A. Facial Anti-Aging Treatments with Soft Peeling and Microneedling Technique. Appl. Sci. 2021, 11, 6068. https://doi.org/10.3390/app11136068

Academic Editor: Wanda Lattanzi

Received: 29 May 2021

Accepted: 23 June 2021

Published: 30 June 2021

Publisher's Note: MDPI stays neutral with regard to jurisdictional claims in published maps and institutional affiliations.

Copyright: (c) 2021 by the authors Licensee MDPI, Basel, Switzerland. This article is an open access article distributed under the terms and conditions of the Creative Commons Attribution (CC BY) license (https:// creativecommons.org/licenses/by/ $4.0 /)$.

\begin{abstract}
Background: The interest in maintaining a young and attractive appearance in an era with increasingly hectic rhythms has generated a pressing demand for effective aesthetic procedures with the shortest possible recovery period, stimulating the search for non-invasive, yet successful, solutions. The aim of this study was to evaluate the effectiveness of the combined soft peeling and MN technique on the various imperfections typical of facial aging. Methods: This multicentric uncontrolled experimental study recruited a population of healthy subjects of both sexes with advanced signs of photo- and chrono-aging. These subjects were provided with a single session of microneedling and peeling at the same time. Recruited subjects were re-evaluated $30( \pm 4)$ and $60( \pm 4)$ days after treatment by photographic comparison before and after treatment. The physicians evaluated the improvement of facial wrinkles according to the Wrinkle Assessment Scale of Lemperle. Forty-nine subjects completed the study and showed a significant improvement in wrinkles in all areas of the face. Results: There were no significant differences in the different subpopulations compared: males-females, Glogau 3-Glogau 4, smokers-non-smokers, phototypes 1-4, and check up at 30 days-control at 60 days. The adverse events manifested were localized edema in four cases $(8.2 \%)$ lasting an average of 3-4 days, very fine crustiness in four cases $(8.2 \%)$, transient post inflammatory dyschromia in two cases (4.1\%) lasting 2-3 weeks, and herpetic reactivation in one case $(2.0 \%)$. Conclusions: The study demonstrates the therapeutic efficacy of the combined needling-peeling treatment in different types of wrinkles.
\end{abstract}

Keywords: fractional peeling; microneedling; percutaneous collagen induction; antiaging; peppermint peel; biorivitalization

\section{Introduction}

The interest in maintaining a young and attractive appearance in an era with increasingly hectic rhythms has generated a pressing demand for effective aesthetic procedures associated with the shortest possible recovery period, stimulating the search for non-invasive, yet successful, solutions. Different endogenous stressors (e.g., endocrine-metabolic diseases) and/or exogenous stressors (e.g., ultraviolet radiation) can be the cause of skin functional alterations and/or structural problems that can damage skin integrity to varying degrees of severity [1]. Patients seeking treatment to rejuvenate photodamaged skin want 
to reduce pigmentation irregularities, have a smooth texture, reduce wrinkles, and improve skin laxity. Many techniques have been proposed for the treatment and prevention of facial aging, such as laser resurfacing [1,2], deep chemical peels [3], and dermabrasion [4], which involves the destruction of the epidermis, with damage to the dermis, and consequently initiates an inflammatory response, resulting in the production of new collagen, vascular texture and skin regeneration. However, the use of these techniques is often associated with the production of thicker bundles of collagen, transient alteration of the ratio between type 1 and type 3 collagen, alteration of the morpho-structural conformation of the bundles of fibers [5-8], and a greater susceptibility to photo damage with the possibility of postinflammatory hyperpigmentation and post-procedural complications $[9,10]$. Non-ablative alternatives that avoid these types of complications and reduce recovery time include peeling and microneedling (MN), and percutaneous collagen induction (PCI), a technique that uses a manual or motorized microneedle device. The motorized MN is equipped at the tip with disposable sterile cartridges containing micro needles in a variety of numbers, and this allows the depth and frequency of penetration to be adjusted depending on the indication and the area to be treated. By sliding the device over the skin, microperforations of the skin are created, triggering a controlled post-traumatic inflammatory response (with the simultaneous release of growth factors and the formation of collagen and elastin) [11-13]. In addition to the aforementioned intrinsic capabilities related to the penetration of the needle alone with consequent mechanical trauma, $\mathrm{MN}$ can also be used to convey substances and drugs applied to the skin surface. The transdermal administration of therapeutics is severely limited by the poor permeability of human skin; most molecules do not cross the skin at therapeutically relevant rates. Since the stratum corneum has a variable thickness of a few tens of micrometers, the microneedles have a length of a few hundred microns and are therefore able to cross the transcorneal barrier and provide transport routes to the underlying tissues [14,15].

Peeling as an anti-aging technique is relatively recent and increasingly used. From the use of single acids, we have moved on to formulations composed of combinations of different acids, in specific concentrations to ensure greater effectiveness of the treatment at the proposed target (the so-called compound peelings, or combinations of multiple substances in the same device) [16]. Compound peels, in addition to their specificity, offer the advantage of a synergistic effect between the different substances [17]. Superficial peels, combined and not combined, have allowed a drastic reduction in the onset of adverse events typical of medium and deep peels, such as systemic toxicity (e.g., phenol), posttreatment hyperpigmentation, hypopigmentation, keloids, erythema, telangiectasiae, millet grains, infections, and herpetic reactivations [18]. Superficial peels have a limited effect on the epidermis as they do not involve systemic absorption or diffusion into the underlying tissues (dermis and hypodermic adipose tissue). Nevertheless, it has been shown that superficial peels induce a rejuvenating effect through the mechanical stimulation of the skin stress response system (SSRS), a system dedicated to repairing damaged tissue and restoring normal homeostasis [19].

The rationale for the combined use of $\mathrm{MN}$ with soft peeling consists of the synergistic effect of both therapeutic methods in order to increase efficacy without prolonging the recovery time: $\mathrm{MN}$ induces controlled mechanical trauma, stimulating epidermis and dermis tissue through a reparatory process, and creating microchannels that can enable preparations applied to the skin to go beyond the cornea barrier, increasing their absorption; the soft peeling carries out a chemical effect capable of breaking the intercellular bonds and causing desquamation, stimulating the inflammatory process, inducing cell damage with necrosis, favoring turnover, activation of SSRS, and neofibrillogenesis. The microchannels of the needling convey the peeling into the dermal layer, favoring deep damage and sparing the tissues surrounding each wound, as around the microchannel there is healthy uninjured tissue, which facilitates healing and the restoration of normal physiology. This recalls the rationale of fractional photothermolysis with laser [20] or of resurfacing with voltaic arc dermabrasion [21-24]; for this reason it can be called "fractional peeling". In 
fact, combined procedures are used for the treatment of many cosmetic skin problems such as the treatment of skin laxity, post-acne scars, hyperkinetic facial wrinkles, and hyperpigmentation disorders [25]. Today, many authors use MN combined with plateletrich plasma for the treatment of atrophic acne scars [26] and other blemishes [27].

The study evaluated the effectiveness of the combined soft peeling and $\mathrm{MN}$ technique in the various imperfections typical of facial aging.

\section{Materials and Methods}

This multicenter uncontrolled experimental study recruited a population of healthy subjects of both sexes with advanced signs of photo- and chrono-aging (Glogau 3 and 4) [28], phototype 1 to 4 according to Fitzpatrik [29]. The study protocol was performed in accordance with the European Union GCP Standards of Clinical Practice and the ethical principles expressed in the Declaration of Helsinki [30]. A total 56 subjects between the ages of 42 and 73 (average 56.18) were treated: 38 women and 11 men completed the study and were evaluated at 30 and 60 days after treatment; 7 subjects were excluded from the study as they did not perform the check-up in the pre-established timing, and 3 subjects experienced an acute inflammatory pathology that led to the intake of medications, and therefore were not considered suitable for evaluation. These 3 subjects were excluded for follow up because two had a gastrointestinal affection (two sisters) and one had multiple extensive abrasions from falling off a motorcycle. The subjects were enrolled from 1 October 2019 to 31 October 2019. The study started on 1 November 2019 and ended on 28 February 2020. During the period from recruitment (one week before treatment) to the second and last evaluation (60 days after treatment), patients considered suitable for evaluation did not undergo any concomitant therapy, did not manifest any pathologies, and were not subjects of aesthetic treatments on the face.

The recruitment of the candidates involved an initial interview to evaluate the criteria for inclusion and exclusion from the study. Inclusion criteria were aging signs classified in classes 3 (wrinkles present even at rest) and 4 (wrinkles everywhere) of the Glogau photo-aging scale, phototype from 1 to 4 according to the Fitzpatrick classification. General exclusion criteria excluded candidates who: were below the age of 18 , were pregnant or breastfeeding, had known allergies to one or more of the active ingredients of the peeling, suffered from serious or skin-related autoimmune diseases, were experiencing acute infections, were in a state of immunosuppression, had hemorrhagic diathesis, required oral anticoagulant therapy, had platelet disorders, had a tendency to develop hypertrophic scars, keloids or skin inflammations, or had undergone any aesthetic treatments in the last 3 months (fillers, threads, peels, lasers, etc.). Specific exclusion criteria in the area to be treated were: ongoing acute pathologies (inflammation, burns, continuous solutions, acute dermatological lesions), infections (including herpetic reactivations) and skin tumors, and permanent implants or foreign bodies in the area to be treated.

The doctor who recruited the suitable subject, after giving information about the study, then: (i) evaluated the facial features, (ii) filled in the facial wrinkle evaluation form assigning each type a value from 1 to 5 according to the scale of evaluation of Lemperle [25] (Table 1), (iii) filled in the anamnestic form and the clinical data sheet, (iv) took the photos for the evaluation, and (v) collected the forms previously given to the patient (information sheet, informed consent, personal data management sheet). 
Table 1. Evaluation of the facial wrinkles of patients according to the Lemperle rating scale before treatment.

\begin{tabular}{|c|c|c|c|c|c|c|}
\hline $\begin{array}{c}\text { FACIAL } \\
\text { WRINKLE }\end{array}$ & $\begin{array}{c}\text { Class } 0 \\
\text { no Wrinkles }\end{array}$ & $\begin{array}{c}\text { Class } 1 \\
\text { Just } \\
\text { Perceptible } \\
\text { Wrinkle }\end{array}$ & $\begin{array}{c}\text { Class } 2 \\
\text { Shallow } \\
\text { Wrinkles }\end{array}$ & $\begin{array}{c}\text { Class } 3 \\
\text { Moderately } \\
\text { Deep Wrinkle }\end{array}$ & $\begin{array}{c}\text { Class } 4 \\
\text { Deep Wrinkle, } \\
\text { Well-Defined } \\
\text { Edges }\end{array}$ & $\begin{array}{c}\text { Class } 5 \\
\text { Very Deep } \\
\text { Wrinkle, } \\
\text { Redundant } \\
\text { Fold }\end{array}$ \\
\hline $\begin{array}{l}\text { Horizontal } \\
\text { forehead lines }\end{array}$ & 0 & 0 & 0 & 16 & 20 & 13 \\
\hline $\begin{array}{c}\text { Glabellar frown } \\
\text { lines }\end{array}$ & 0 & 0 & 0 & 21 & 14 & 14 \\
\hline Periorbital lines & 0 & 0 & 2 & 18 & 19 & 10 \\
\hline $\begin{array}{l}\text { Preauricular } \\
\text { lines }\end{array}$ & 0 & 0 & 0 & 38 & 4 & 7 \\
\hline Cheek lines & 0 & 0 & 1 & 13 & 27 & 8 \\
\hline $\begin{array}{l}\text { Nasolabial } \\
\text { folds }\end{array}$ & 0 & 0 & 8 & 14 & 16 & 11 \\
\hline $\begin{array}{l}\text { Radial upper } \\
\text { lip lines }\end{array}$ & 0 & 0 & 5 & 9 & 12 & 23 \\
\hline $\begin{array}{c}\text { Radial lower lip } \\
\text { lines }\end{array}$ & 0 & 0 & 17 & 13 & 14 & 5 \\
\hline $\begin{array}{l}\text { Corner of the } \\
\text { mouth lines }\end{array}$ & 0 & 0 & 9 & 13 & 11 & 16 \\
\hline $\begin{array}{l}\text { Marionette } \\
\text { lines }\end{array}$ & 0 & 0 & 2 & 12 & 12 & 23 \\
\hline $\begin{array}{l}\text { Labiomental } \\
\text { crease }\end{array}$ & 0 & 0 & 6 & 22 & 14 & 7 \\
\hline
\end{tabular}

For microneedling, an automatic device consisting of a handpiece and a cartridge consisting of 6 sterile disposable stainless steel microneedles (maximum length $1.5 \mathrm{~mm}$, $0.35 \mathrm{~mm}$ caliber) was used. The handpiece contained an engine that moved the cartridge needles and a needle depth gauge, allowing the user to control the penetration depth of the needle from 0 to $1.5 \mathrm{~mm}$. The control unit allowed the user to adjust the needle stroke frequency from 100 to $150 \mathrm{~Hz}$. Peppermint Peel-Intense (PMP) (Marc Medical srl, Cecina, Italy) was used for the soft peeling. PMP is a soft peel used exclusively for medical use, specifically for subjects with signs of photo- and chrono-aging. It is composed of specific peeling acids (19\% non-buffered trichloracetic acid, glycolic acid, malic acid, lactic acid, salicylic acid), moisturizers (panthenol, betaine, pyroglutamic acid), aesthetic enhancers (acetyl hexapeptide 19), and menthol. Before performing the treatment, the skin was thoroughly cleansed and any make-up or creams removed. Then, $2.5 \mathrm{~mL}$ of anesthetic cream (galenic preparation with $10 \%$ lidocaine, $2.5 \%$ prilocaine, $2.5 \%$ tetracaine) was applied to the face and removed after $30 \mathrm{~min}$. The skin was disinfected with a gauze soaked in a chlorhexidine-based disinfectant solution. With a syringe equipped with a needle, the rubber stopper was pierced and $2.5 \mathrm{~mL}$ of PMP was taken from the vial. For a homogeneous distribution of the soft peel and for a better management of the exposure times, the face was divided into 3 subunits: upper third, middle third and lower right, middle third and lower left. Each of these subunits was treated individually in the same session. An amount equal to $0.5 \mathrm{~mL}$ was distributed in a subunit with the fingers of the hand, covered by a nitrile glove, just before performing the microneedling. During the microneedling procedure, different needle penetration lengths were used in different areas: $0.7-1.0 \mathrm{~mm}$ in the perilabial and periocular areas, $0.9-1.3 \mathrm{~mm}$ on the forehead, chin, glabella and jawline, $1.2-1.5 \mathrm{~mm}$ in the preauricular, zygomatic and subzygomatic, malar and submalar regions. The handpiece was placed on the skin. The hand applied 
constant pressure on the handpiece while circular movements were performed with even distribution throughout the area to be treated. The end point for microneedling was to obtain homogeneous bleeding in the treated area. At the end of the microneedling, the leaking blood was removed and the peeling solution was applied again in a quantity sufficient to cover the treated area $(0.3 \mathrm{~mL})$ and was left on for $5 \mathrm{~min}$.

After the treatment, for 7 days, a restructuring serum (BioReHydra-CMed Aesthetics, Pisa, Italy) was applied, prolonged exposure to the sun was avoided, sun beds were not used, and particularly intense physical activity, extreme climatic conditions, and the application of topical products, other than make-up, were avoided.

Recruited subjects were re-evaluated $30( \pm 4)$ and $60( \pm 4)$ days after treatment by photographic comparison before and after treatment. To maintain the study in blind mode, the patients were evaluated by two doctors who (i) had not performed the same treatment and (ii) were provided with no additional information regarding the individual being treated. The physicians evaluated the improvement of facial wrinkles according to the Wrinkle Assessment Scale of Lemperle (Table 1) [31].

\section{Results}

The study recruited 56 subjects between the ages of 42 and 73 (average 56.18). Of these subjects, 38 women and 11 men completed the study and were evaluated at 30 and 60 days after treatment, while 4 subjects who did not perform the check within the pre-established timing and 3 subjects who experienced the onset of an acute inflammatory pathology that led to the intake of medication, were not considered suitable for evaluation. The evaluations showed a significant improvement in wrinkles in all areas of the face (Table 2). There were no significant differences in the different subpopulations compared: malesfemales, Glogau 3-Glogau 4, smokers-non smokers, phototypes 1-4, or subjects who had their check up at 30 days-control group who had their check up at 60 days. The wrinkles that benefited most from the treatment were those originating from the modification of the dermis and the dermal-epidermal junction, such as cheek and periauricular wrinkles, and those due to the structural modification of the subcutaneous loose connective tissue with the interaction of gravity, such as the lines of the corners of the mouth and the nasolabial folds (Scheme 1). The wrinkles that benefited the least were those induced by mimic muscles, such as forehead wrinkles, barcode wrinkles, and glabellar wrinkles (Figures 1-4 and Scheme 1).

Table 2. Comparison between the average values resulting from the medical evaluation (carried out according to the Lamperle rating scale, Table 1) before treatment, at 30 days post-treatment and at 60 days post-treatment. The last 2 columns show the values of the degree of improvement after 30 days (1) and after 60 days (2).

\begin{tabular}{cccccc}
\hline Facial Wrinkle & Pre-Treatment & $\begin{array}{c}\text { 30 Days } \\
\text { Post-Treatment }\end{array}$ & $\begin{array}{c}\text { 60 Days } \\
\text { Post-Treatment }\end{array}$ & $\begin{array}{c}\text { Grade of } \\
\text { Improvement (1) }\end{array}$ & $\begin{array}{c}\text { Grade of } \\
\text { Improvement } \\
\text { (2) }\end{array}$ \\
\hline Horizontal forehead lines & $3.938 \pm 0.77$ & $3.367 \pm 0.67$ & $3.388 \pm 0.68$ & 0.571 & 0.551 \\
$\quad$ Glabellar frown lines & $3.857 \pm 0.84$ & $3.082 \pm 0.73$ & $3.122 \pm 0.70$ & 0.776 & 0.735 \\
$\quad$ Periorbital lines & $3.755 \pm 0.83$ & $2.775 \pm 0.55$ & $2.775 \pm 0.55$ & 0.975 & 0.989 \\
Preauricular lines & $3.367 \pm 0.73$ & $2.286 \pm 0.74$ & $2.265 \pm 0.73$ & 1.082 & 1.102 \\
$\quad$ Cheek lines & $3.857 \pm 0.70$ & $2.714 \pm 0.89$ & $2.735 \pm 0.91$ & 1.143 & 1.123 \\
$\quad$ Nasolabials fold & $3.612 \pm 1.02$ & $2.755 \pm 0.85$ & $2.775 \pm 0.87$ & 0.857 & 0.837 \\
Radial upper lip lines & $4.081 \pm 1.04$ & $3.429 \pm 0.84$ & $3.449 \pm 0.84$ & 0.653 & 0.632 \\
Radial lower lip lines & $3.142 \pm 1.02$ & $2.306 \pm 0.87$ & $2.306 \pm 0.87$ & 0.836 & 0.836 \\
Corner of the mouth lines & $3.694 \pm 1.12$ & $2.775 \pm 0.92$ & $2.734 \pm 0.93$ & 0.919 & 0.959 \\
$\quad$ Marionette lines & $4.143 \pm 0.93$ & $3.347 \pm 0.85$ & $3.347 \pm 0.88$ & 0.796 & 0.795 \\
Labiomental crease & $3.449 \pm 0.89$ & $2.612 \pm 0.70$ & $2.632 \pm 0.72$ & 0.837 & 0.816 \\
\hline
\end{tabular}




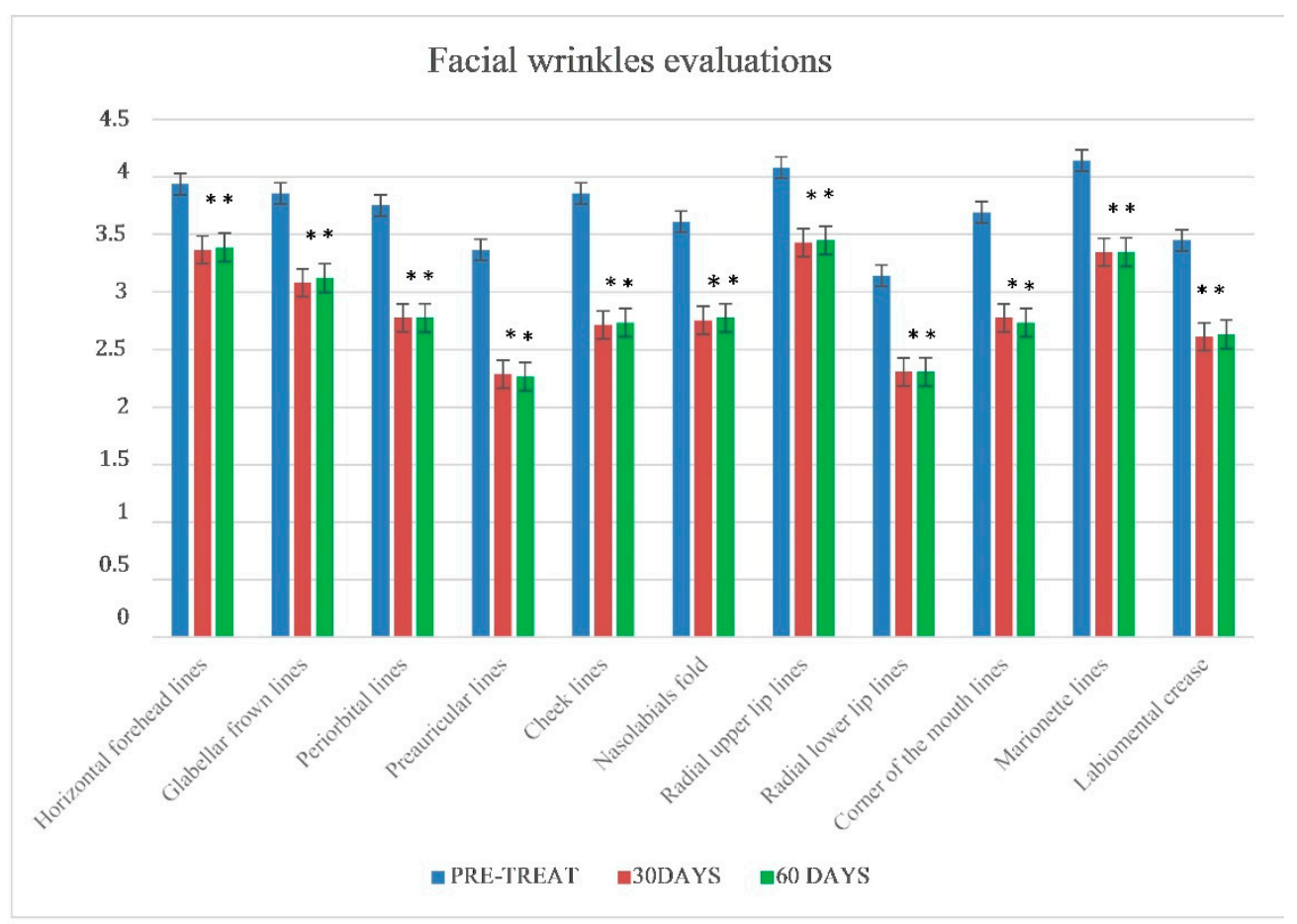

Scheme 1. Graphical representation of data reported in Table 2. Significance was calculated using a paired $T$-test. ${ }^{*} p<0.05$ vs. pre-treatment.
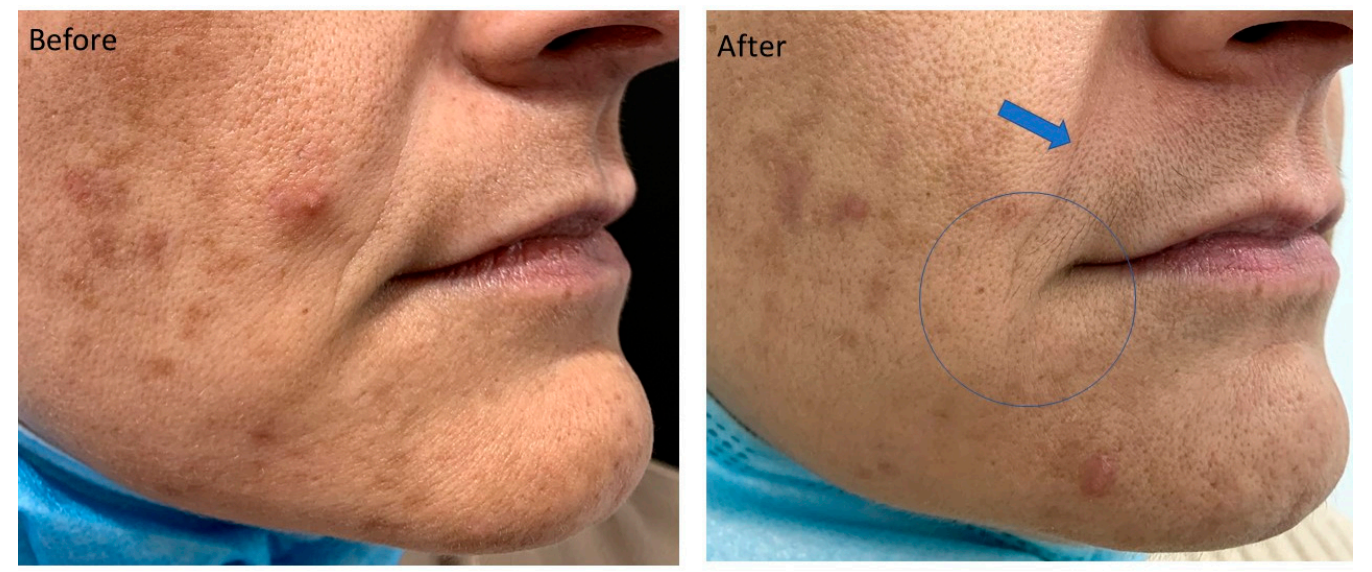

Figure 1. Female patient, Glogau 3, phototype 3, 42 years old. The treatment showed an improvement of 2 points on the corner of the mouth line (arrow) and 1 point on the nasolabial fold (blue circle). Even though it was not evaluated in this study, the treatment brought benefits in subjects with active acne, as in this case. 

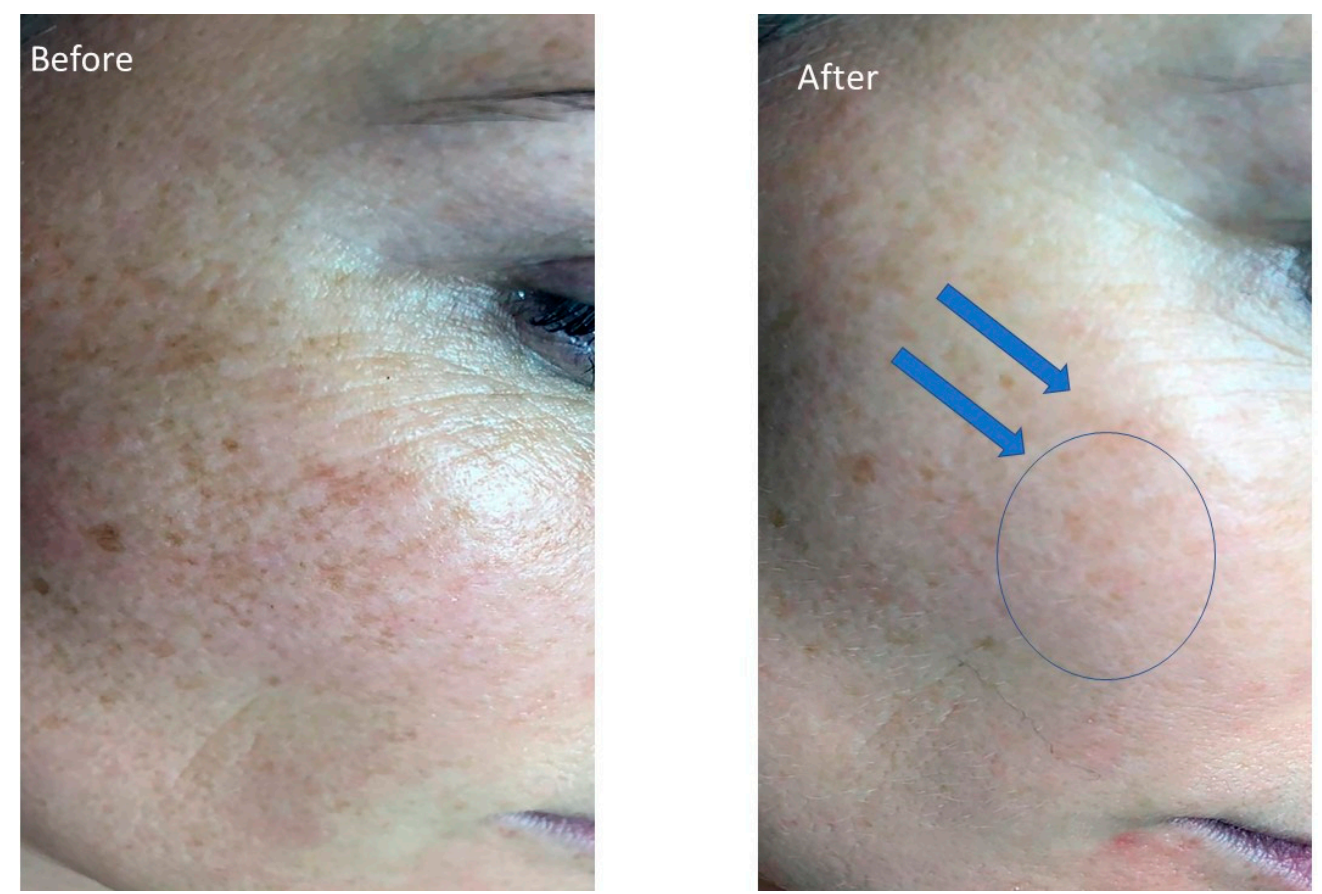

Figure 2. Female patient, Glogau 3, phototype 2, 51 years old, with many expression lines (also present at rest), and dyschromia. The improvement of periocular wrinkles of 1 point (arrows) was associated with the improvement of hyperchromic spots, another typical sign of advanced facial aging (blue circle).

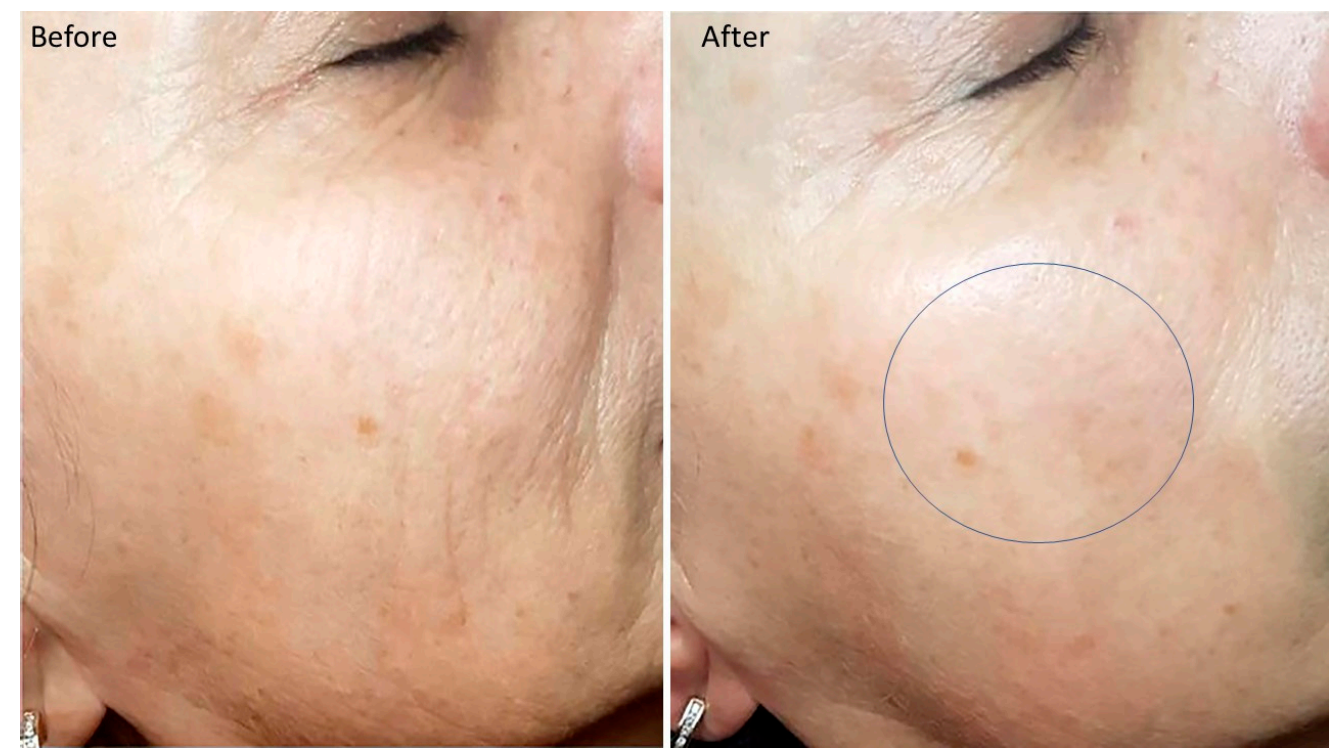

Figure 3. Female patient, Glogau 3, phototype 2, 64 years old, in whom superficial wrinkles predominate as signs of advanced aging. The cheek lines improved by 1 point (blue circle). 

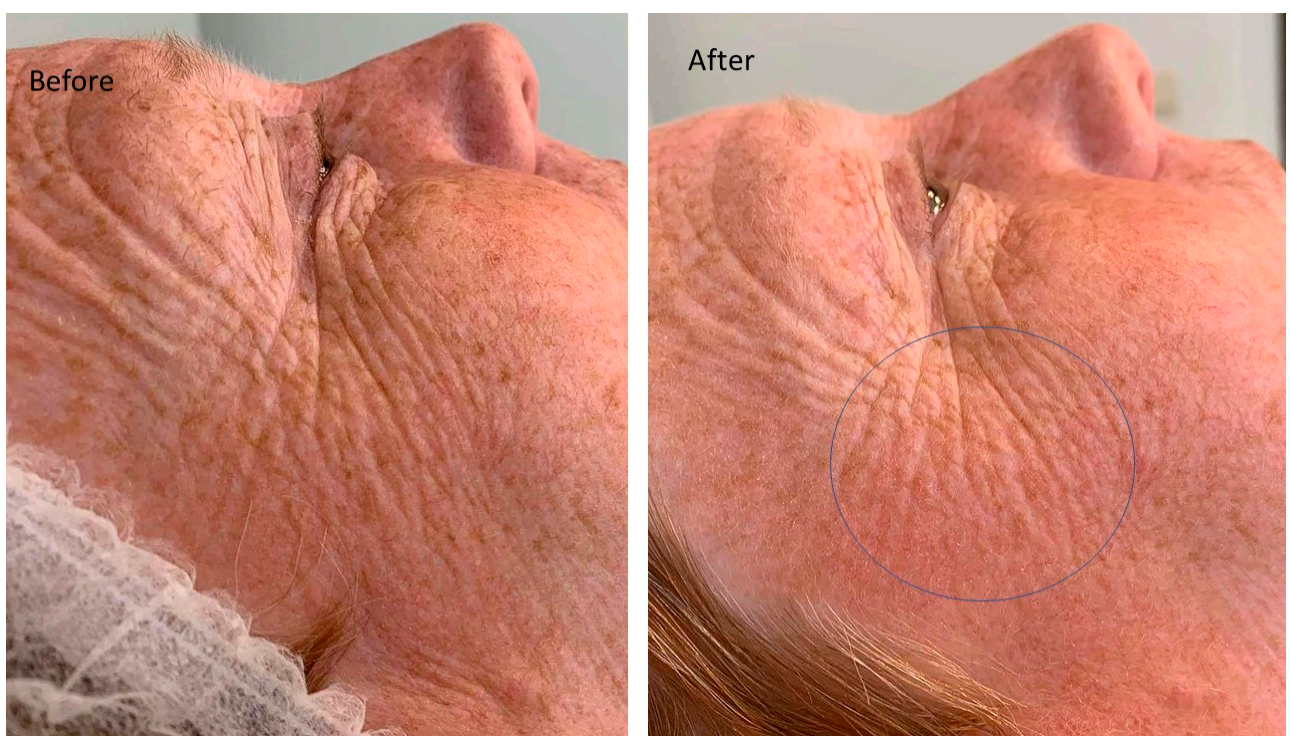

Figure 4. Female patient, Glogau 4, phototype 2, 71 years old, in whom elastosis predominates. The periocular, preauricular wrinkles improved by 1 point (blue circle).

The treatment had an average recovery time of 6.3 days $( \pm 2.3)$ which involved, in chronological order: erythema, hypersensitivity and skin hyperreactivity in the first phase (2-3 days), then subsequent desquamation with transient discoloration (due to the presence of desquamated areas with non-desquamated areas).

The adverse events manifested were localized edema in four cases ( $8.2 \%)$, lasting an average of 3-4 days, very fine crustiness in four cases (8.2\%), transient post inflammatory dyschromia in two cases $(4.1 \%)$, lasting $2-3$ weeks, and herpetic reactivation in one case $(2.0 \%)$.

\section{Discussion}

The study demonstrated the therapeutic efficacy of the combined needling-peeling treatment in different types of wrinkles (Figures 1-4). The maintenance of the integrity of the epidermal layer associated with the deep damage and the restriction of this damage to the area delimited by the microchannel, sparing the surrounding tissues, determines a good therapeutic result, with a low risk of side effects and complications [32,33].

Combined MN-Peeling protocols have already been proposed in the past [34,35]; combined treatments of micro-needling with platelet rich plasma or TCA $15 \%$ have shown significant improvements when compared with micro-needling alone. However, the studies proposing the use of combined MN-peeling protocols did not examine the simultaneous use of both. In this study, the mechanical damage-chemical damage association proved to be synergistic, highly effective, and well tolerated by the treated subjects. The greater aggressiveness induced by the delivery of the peeling directly under the stratum corneum through the microchannels was, however, controlled by the surrounding healthy intact regions and by the non-acid components of the PMP device. The ingredients panthenol, betaine, pyroglutamic acid and acetyl hexapeptide 19 present in the soft peeling allowed a reduction in the transient state of xerosis induced by the peeling acids, promoting the restoration of homeostasis and NMF and reducing the post-treatment phase, giving an immediate effect of smooth and soft skin [36-40].

However, the technique has some aspects to take into consideration: (i) compared to the single techniques, soft peeling and $\mathrm{MN}$, the combined technique involves an average recovery time of about 6 days, characterized by erythema, hyperemia, desquamation and hypersensitivity. The single techniques, on the other hand, involve minimal, or even no, recovery time [11,17]; (ii) the $\mathrm{MN}$ technique is operator dependent, the intensity of the treatment is based not only on the frequency and length of penetration of the microneedles 
or parameters set on the motorized device, but also on the pressure exerted by the doctor on the handpiece during the treatment and the number of micro-perforations per unit of treated area (density); and (iii) the cut off is established by the physician's clinical judgment on the basis of visible micro bleeding [41].

Structural changes in the collagen and skin lipid matrix, deterioration of elastin, dermal and epidermal atrophy, contractions of the connective membranous septae are the main processes responsible for superficial wrinkles [42]. Fractional peeling (microneedling combined with soft peeling) has been shown to be effective in fighting these processes by significantly reducing the signs they cause. The concept of controlled deep damage limited to an area surrounded by uninjured healthy tissue has already been used by other technologies, such as $\mathrm{CO}_{2}$ laser resurfacing and voltaic arc dermabrasion, to improve results and reduce recovery time; this study shows that the same concept can also be successfully applied to the combined MN-soft peeling technique.

\section{Conclusions}

The limitation of this research was the lack of a control group treated with only a soft peel or microneedling monotherapy. In conclusion, the outcomes of this study demonstrate the therapeutic efficacy of the combined microneedling-peeling treatment on different types of wrinkles and suggest that combined microneedling-peeling treatment constitutes a good treatment with encouraging results and minor side-effects.

Author Contributions: Conceptualization, A.S. (Antonio Scarano), R.A.; methodology, R.A., A.S. (Andrea Sbarbati), F.D., A.S. (Antonio Scarano), D.A., M.V.; software, A.S. (Antonio Scarano), F.D., A.S., I.P., A.P.; validation, A.S. (Andrea Sbarbati), R.A., D.A.; formal analysis, F.D., A.S. (Andrea Sbarbati), D.A., M.V., I.P., A.P.; investigation, A.S. (Antonio Scarano), A.P., I.P.; data curation, R.A., A.S. (Andrea Sbarbati), D.A.; writing—original draft preparation, A.S. (Antonio Scarano), R.A., D.A.; writing-review and editing, A.S. (Antonio Scarano), R.A., F.D., A.S. (Andrea Sbarbati), D.A. All authors have read and agreed to the published version of the manuscript.

Funding: This research received no external funding.

Institutional Review Board Statement: The study protocol was performed in accordance with the European Union GCP Standards of Clinical Practice and the ethical principles expressed in the Declaration of Helsinki.

Informed Consent Statement: Informed consent was obtained from all subjects involved in the study. Written informed consent has been obtained from the patients to publish this paper.

Data Availability Statement: All experimental data to support the findings of this study are available contacting the corresponding author upon request.

Acknowledgments: The authors declare no acknowledgment for the present investigation.

Conflicts of Interest: The authors declare no conflict of interest.

\section{References}

1. Dover, J.S.; Hruza, G.J. Laser skin resurfacing. Semin. Cutan. Med. Surg. 1996, 15, 177-188. [CrossRef]

2. Gold, M.H. Update on Fractional Laser Technology. J. Clin. Aesthet. Dermatol. 2010, 3, 42-50.

3. Fulton, J.E., Jr.; Porumb, S. Chemical Peels. Am. J. Clin. Dermatol. 2004, 5, 179-187. [CrossRef] [PubMed]

4. Atkins, D.; Frodel, J. Skin Rejuvenation in Facial Surgery. Facial Plast. Surg. 2006, 22, 129-139. [CrossRef]

5. Orringer, J.S.; Rittié, L.; Hamilton, T.; Karimipour, D.J.; Voorhees, J.J.; Fisher, G.J. Intraepidermal erbium:YAG laser resurfacing: Impact on the dermal matrix. J. Am. Acad. Dermatol. 2011, 64, 119-128. [CrossRef]

6. El-Domyati, M.; Abd-El-Raheem, T.; Medhat, W.; Abdel-Wahab, H.; Al Anwer, M. Multiple fractional erbium: Yttrium-aluminumgarnet laser sessions for upper facial rejuvenation: Clinical and histological implications and expectations. J. Cosmet. Dermatol. 2014, 13, 30-37. [CrossRef] [PubMed]

7. Ren, X.; Ge, M.; Qin, X.; Xu, P.; Zhu, P.; Dang, Y.; Gu, J.; Ye, X. S100a8/NF-kB signal pathway is involved in the 800-nm diode laser-induced skin collagen remodeling. Lasers Med. Sci. 2016, 31, 673-678. [CrossRef] [PubMed]

8. Ye, X.; Wang, L.; Dang, Y.; Liu, B.; Zhao, D. Investigation of the $1064 \mathrm{~nm}$ Q-Switched Nd:YAG Laser on Collagen Expression in an Animal Model. Photomed. Laser Surg. 2012, 30, 604-609. [CrossRef] [PubMed] 
9. Bernstein, L.J.; Kauvar, A.N.B.; Grossman, M.C.; Geronemus, R.G. The Short- and Long-Term Side Effects of Carbon Dioxide Laser Resurfacing. Dermatol. Surg. 1997, 23, 519-525. [CrossRef]

10. Kauvar, A.N.; Geronemus, R.G. Histology of laser resurfacing. Dermatol. Clin. 1997, 15, 459-467. [CrossRef]

11. Fernandes, D.; Signorini, M. Combating photoaging with percutaneous collagen induction. Clin. Dermatol. 2008, 26, 192-199. [CrossRef] [PubMed]

12. Fernandes, D. Minimally Invasive Percutaneous Collagen Induction. Oral Maxillofac. Surg. Clin. N. Am. 2005, 17, 51-63. [CrossRef] [PubMed]

13. Ablon, G. Safety and Effectiveness of an Automated Microneedling Device in Improving the Signs of Aging Skin. J. Clin. Aesthet. Dermatol. 2018, 11, 29-34.

14. Henry, S.; McAllister, D.V.; Allen, M.G.; Prausnitz, M.R. Microfabricated Microneedles: A Novel Approach to Transdermal Drug Delivery. J. Pharm. Sci. 1998, 87, 922-925. [CrossRef]

15. Duncan, D.I. Microneedling with Biologicals. Facial Plast. Surg. Clin. N. Am. 2018, 26, 447-454. [CrossRef]

16. Brody, H.J. Trichloroacetic acid application in chemical peeling. Oper. Tech. Plast. Reconstr. Surg. 1995, 2, 127-128. [CrossRef]

17. Scarano, A.; Amodeo, V.; Leonardi, V.; Mortellaro, C.; Sbarbati, A.; Amuso, D.; Amore, R.; Pagnini, D. Evaluation of the Ef-fectiveness and Safety of Peppermint Peel (PMP) Soft Peeling for Skin Ageing. J. Biol. Regul. Homeost. Agents 2019, 33, 93-101.

18. Lober, C.W. Chemexfoliation-Indications and cautions. J. Am. Acad. Dermatol. 1987, 17, 109-112. [CrossRef]

19. Kimura, A.; Kanazawa, N.; Li, H.-J.; Yonei, N.; Yamamoto, Y.; Furukawa, F. Influence of chemical peeling on the skin stress response system. Exp. Dermatol. 2012, 21, 8-10. [CrossRef]

20. Manstein, D.; Herron, G.S.; Sink, R.K.; Tanner, H.; Anderson, R.R. Fractional Photothermolysis: A New Concept for Cutaneous Remodeling Using Microscopic Patterns of Thermal Injury. Lasers Surg. Med. 2004, 34, 426-438. [CrossRef]

21. Scarano, A.; Carinci, F.; Festa, F.; Dds, V.C.; Amore, R.; Lorusso, F. Periauricular wrinkles removed with voltaic arc dermabrasion (Atmospheric Plasma technique). J. Cosmet. Dermatol. 2020, 19, 1709-1714. [CrossRef]

22. Scarano, A.; Carinci, F.; Candotto, V.; Lorusso, F. Eradication of Benign Skin Lesions of the Face by Voltaic Arc Dermabrasion (Atmospheric Plasma): Postoperative Pain Assessment by Thermal Infrared Imaging. Aesthetic Plast. Surg. 2020, 44, $2277-2285$. [CrossRef]

23. Scarano, A.; Lorusso, F.; Brucoli, M.; Lucchina, A.G.; Carinci, F.; Mortellaro, C. Upper Eyelid Blepharoplasty with Voltaic Arc Dermabrasion. J. Craniofacial Surg. 2018, 29, 2263-2266. [CrossRef] [PubMed]

24. Scarano, A.; Petrini, M.; Dds, F.I.; Lorusso, F.; Ds, D.A. A new technique for the treatment of nasal telangiectasia using atmospheric plasma (voltaic arc dermabrasion): Postoperative pain assessment by thermal infrared imaging. J. Cosmet. Dermatol. 2020, 19, 2912-2918. [CrossRef] [PubMed]

25. Pathania, V.; Oberoi, B.; Shankar, P.; Bhatt, S. Single-handed vampire facial: Combining microneedling with platelet-rich plasma for single-hand use. J. Am. Acad. Dermatol. 2021, 84, e77-e78. [CrossRef]

26. Long, T.; Gupta, A.; Ma, S.; Hsu, S. Platelet-rich plasma in noninvasive procedures for atrophic acne scars: A systematic review and meta-analysis. J. Cosmet. Dermatol. 2020, 19, 836-844. [CrossRef]

27. Abdel-Motaleb, A.A.; Zedan, H.; Mostafa, M.M.; Abu-Dief, E.E.; Gebril, S.M.; Hussein, M.R.A. Combined microneedling with topical application of platelet-rich plasma versus microneedling alone in the treatment of stria distensae: Clinicopathological analysis. J. Dermatol. Treat. 2020, 1-12. [CrossRef]

28. Glogau, R.G. Aesthetic and anatomic analysis of the aging skin. Semin. Cutan. Med. Surg. 1996, 15, 134-138. [CrossRef]

29. Holck, D.E.E.; Ng, J.D. Facial skin rejuvenation. Curr. Opin. Ophthalmol. 2003, 14, 246-252. [CrossRef]

30. World Medical Association Declaration of Helsinki: Ethical principles for medical research involving human subjects. JAMA 2013, 310, 2191-2194. [CrossRef] [PubMed]

31. Lemperle, G.; Holmes, R.E.; Cohen, S.R.; Lemperle, S.M. A Classification of Facial Wrinkles. Plast. Reconstr. Surg. 2001, 108, 1751-1752. [CrossRef] [PubMed]

32. Atiyeh, B.S.; Ghanem, O.A.; Chahine, F. Microneedling: Percutaneous Collagen Induction (PCI) Therapy for Management of Scars and Photoaged Skin-Scientific Evidence and Review of the Literature. Aesthetic Plast. Surg. 2021, 45, 296-308. [CrossRef] [PubMed]

33. Iosifidis, C.; Goutos, I. Percutaneous collagen induction (microneedling) for the management of non-atrophic scars: Literature review. Scars Burn. Health 2019, 5. [CrossRef]

34. El-Domyati, M.; Abdel-Wahab, H.; Hossam, A. Microneedling combined with platelet-rich plasma or trichloroacetic acid peeling for management of acne scarring: A split-face clinical and histologic comparison. J. Cosmet. Dermatol. 2017, 17, 73-83. [CrossRef]

35. Saadawi, A.N.; Esawy, A.M.; Kandeel, A.H.; El-Sayed, W. Microneedling by dermapen and glycolic acid peel for the treatment of acne scars: Comparative study. J. Cosmet. Dermatol. 2019, 18, 107-114. [CrossRef]

36. Fowler, J. Understanding the Role of Natural Moisturizing Factor in Skin Hydration. Pract. Dermatol. $2012,9,36-40$.

37. Harding, C.R.; Watkinson, A.; Rawlings, A.V.; Scott, I.R. Dry skin, moisturization and corneodesmolysis. Int. J. Cosmet. Sci. 2000, 22, 21-52. [CrossRef]

38. Spada, F.; Barnes, T.M.; Greive, K.A. Skin hydration is significantly increased by a cream formulated to mimic the skin's own natural moisturizing systems. Clin. Cosmet. Investig. Dermatol. 2018, 11, 491-497. [CrossRef]

39. Weiss, R.A.; Weiss, M.A. Evaluation of a novel anti-aging topical formulation containing cycloastragenol, growth factors, peptides, and antioxidants. J. Drugs Dermatol. 2014, 13, 1135-1139. 
40. Santos-Caetano, J.P.; Vila, R.; Gfeller, C.F.; Cargill, M.; Mahalingam, H. Cosmetic use of three topical moisturizers following glycolic acid facial peels. J. Cosmet. Dermatol. 2019, 19, 660-670. [CrossRef] [PubMed]

41. Schwarz, M.; Laaff, H. A Prospective Controlled Assessment of Microneedling with the Dermaroller Device. Plast. Reconstr. Surg. 2011, 127, 146e-148e. [CrossRef]

42. Ruiz, M.A.; Clares, B.; Morales, M.E.; Gallardo, V. Evaluation of the Anti-Wrinkle Efficacy of Cosmetic Formulations with an Anti-Aging Peptide (Argireline ${ }^{\circledR}$ ). Ars Pharm 2009, 50, 168-176. 